(C) Elsevier Sequoia S.A., Lausanne - Printed in The Netherlands

\title{
WEAR OF AGED DENTAL COMPOSITES
}

\section{P. L. FAN and J. M. POWERS}

School of Dentistry, The University of Michigan, Ann Arbor, MI 48109 (U.S.A.)

(Received November 28, 1980)

\section{Summary}

Surface morphology and wear characteristics of five dental composites subjected to accelerated aging were investigated. Aging conditions caused degradation of the surface as evidenced by the formation of microcracks and the exposure and loss of filler particles. Wear parameters such as track width, transition load and mode of surface failure caused by single-pass sliding were influenced by aging and by the composition of the composite.

\section{Introduction}

Wear of dental composite restorative materials has been characterized in vitro by single-pass sliding $[1,2]$. Wear patterns and surface morphology of dental composite restorations in vivo have been reported by Kusy and Leinfelder [3] and by O'Brien and Yee [4]. Clinical wear characteristics may result from changes in the surface properties of the composites on aging in the oral environment. Dental composites subjected to accelerated aging in vitro showed changes in surface profile and exposure of filler particles [5]. The wear characteristics of the aged composites differed from the unaged composites in single-pass sliding [6].

The purpose of this investigation was to evaluate the morphology and wear characteristics of dental composites after different amounts of accelerated aging.

\section{Materials and methods}

Two conventional dental composites $\mathrm{C}$ and $\mathrm{PR}$ and three microfilled composites FN, I and SI were used (Table 1). Each composite was mixed according to the manufacturer's instructions and packed into a stainless steel mold $20 \mathrm{~mm}$ in diameter and $1.5 \mathrm{~mm}$ thick. The surfaces were covered with Mylar and the composite was allowed to polymerize for $7 \mathrm{~min}$.

Accelerated aging of the sample disks was performed in a weathering chamber (Weather-Ometer 25-WR, Atlas Electric Devices Co., Chicago, 
TABLE 1

Code, batch number and manufacturer of products tested

\begin{tabular}{llll}
\hline Code & Product & Batch no. & Manufacturer \\
\hline \multicolumn{2}{l}{ Conventional composites } \\
C & Concise & $\begin{array}{l}\text { Paste A, 9K3 } \\
\text { Paste B, 9M3 }\end{array}$ & 3M Co., St. Paul, MN 55101 \\
PR & Profile & $\begin{array}{l}\text { Universal, 47812 } \\
\text { Catalyst, 37901 }\end{array}$ & $\begin{array}{l}\text { S.S. White Dental Products International, } \\
\text { Philadelphia, PA 19102 }\end{array}$ \\
Microfilled composites & & \\
FN & Finesse & $\begin{array}{l}\text { Base, 071279 } \\
\text { Catalyst, 071279 }\end{array}$ & L. D. Caulk Co., Milford, DE 19963 \\
I & Isopast & Base, 661178 \\
Catalyst, 660179 & Vivadent (U.S.A.), Inc., Buffalo, NY 14217 \\
SI & Silar & $\begin{array}{l}\text { Paste A, 9EE1 } \\
\text { Paste B, 9E3 }\end{array}$ & 3M Co., St. Paul, MN 55101 \\
\hline
\end{tabular}

IL 60613) at $43{ }^{\circ} \mathrm{C}$ and $90 \%$ relative humidity with UV radiation (Xenon Burner 12-2881, Atlas Electric Devices Co., Chicago, IL 60613) of 11.2 $\mathrm{mW} \mathrm{\textrm {cm } ^ { - 2 }}$ and intermittent water spray for $18 \mathrm{~min}$ every $120 \mathrm{~min}$. Samples were tested after 300,600 and $900 \mathrm{~h}$ of aging. Samples used as controls were not subjected to accelerated aging but were tested after storage for 7 days in $37{ }^{\circ} \mathrm{C}$ distilled water.

Single-pass sliding experiments on the samples were performed using an apparatus described elsewhere [1]. Four replications were used for each material and time of aging. The surfaces of the dental composites were subjected to the sliding of a diamond hemisphere ( $360 \mu \mathrm{m}$ in diameter) at a sliding speed of $0.25 \mathrm{~mm} \mathrm{~s}^{-1}$. The normal loads ranged from 1 to $10 \mathrm{~N}$ in increments of $1 \mathrm{~N}$. The wear track widths were measured using a calibrated eyepiece in a metallurgical microscope. Optical and scanning electron microscopy were used to examine the modes of surface failure. Classification of the failure modes were as follows: ductile, class 1 ; tensile cracking, class 3 ; extensive chevron formation, class 5 . Classes 2 and 4 were intermediate classifications. Classes 4 and 5 involved a distinct loss of material.

The transition loads for different surface failure classifications were analyzed by the Spearman-Karber statistic [7]. Multiple comparisons of the transition loads for different aging periods within each material were performed using the Student-Newman-Keuls test [8] at the $95 \%$ level of confidence.

\section{Results}

Figures 1 - 4 show the average wear track widths at various normal loads for aged and unaged specimens of PR, FN, I and SI respectively. 

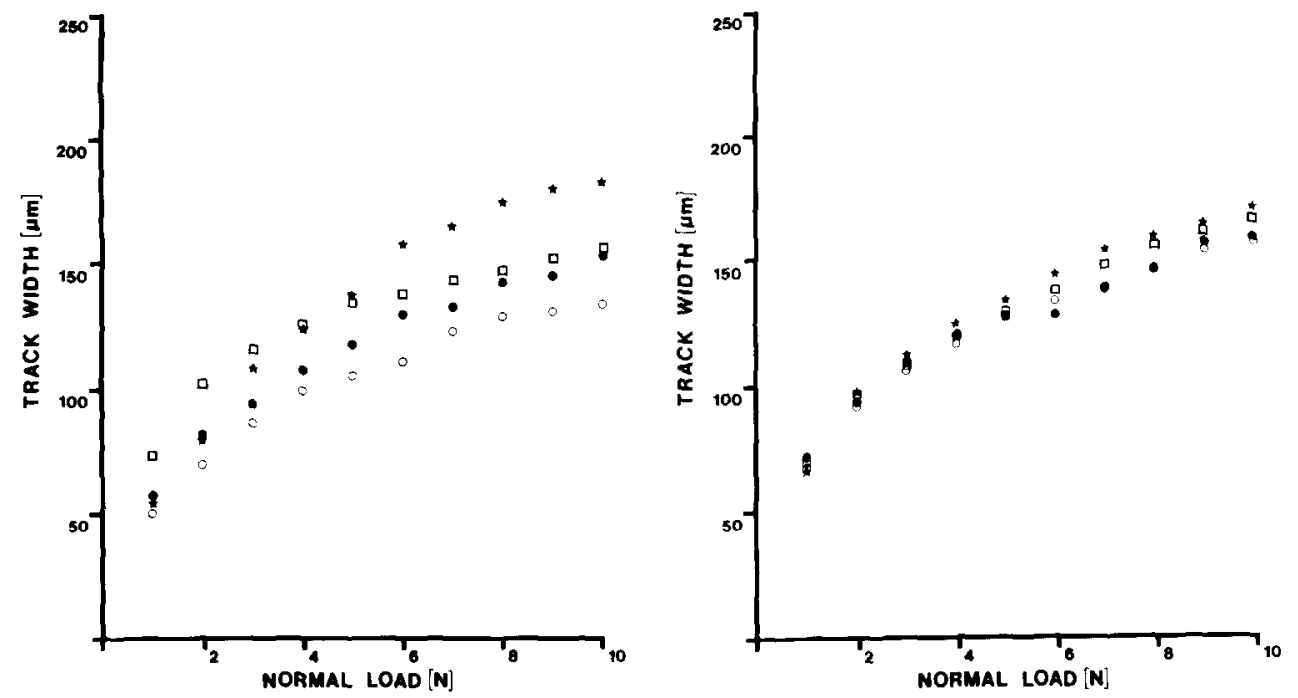

Fig. 1. Wear track widths of PR vs. normal load: $\star, 0 \mathrm{~h} ; 0,300 \mathrm{~h} ; \bullet, 600 \mathrm{~h} ; \square, 900 \mathrm{~h}$.

Fig. 2. Wear track widths of FN vs. normal load: $\star, 0 \mathrm{~h} ; \circ, 300 \mathrm{~h} ; \bullet, 600 \mathrm{~h} ; \square, 900 \mathrm{~h}$.
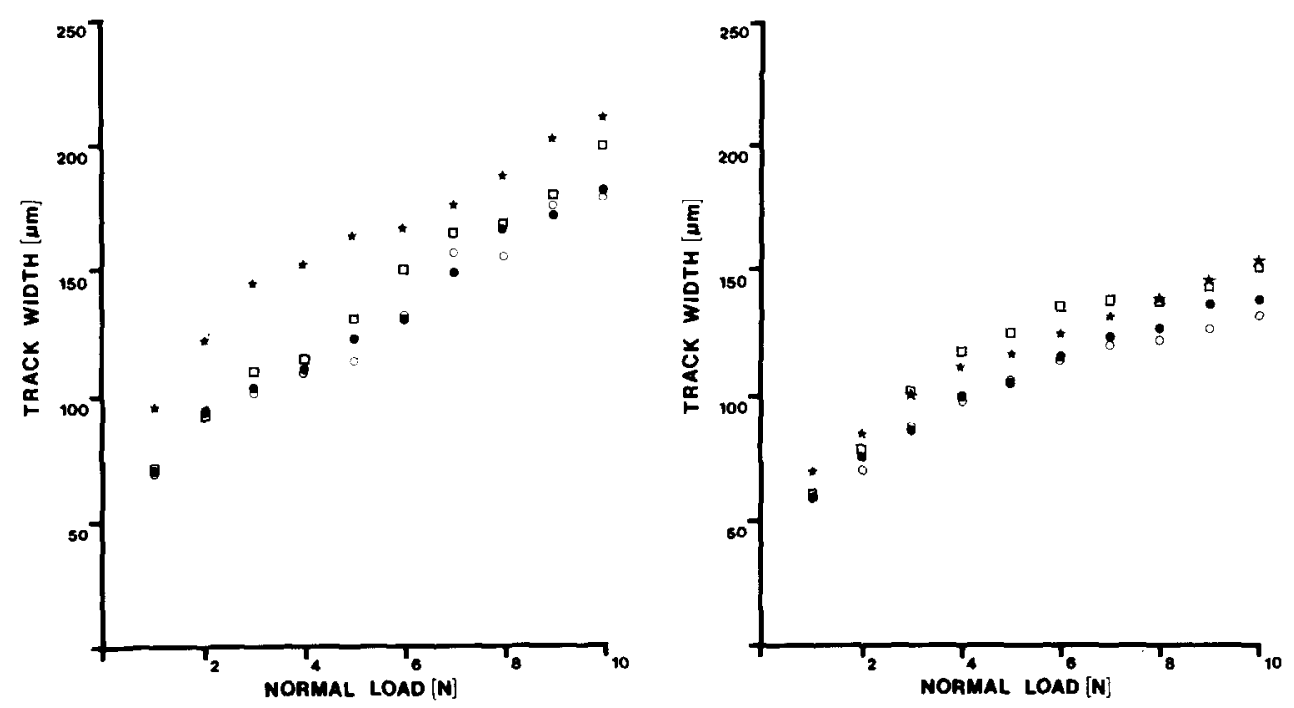

Fig. 3. Wear track widths of I vs. normal load: $\star, 0 \mathrm{~h} ; 0,300 \mathrm{~h} ; \bullet, 600 \mathrm{~h} ; \square, 900 \mathrm{~h}$.

Fig. 4. Wear track widths of SI vs. normal load: $\star, 0 h ; 0,300 h ; \bullet, 600 h ; \square, 900 \mathrm{~h}$. 
C
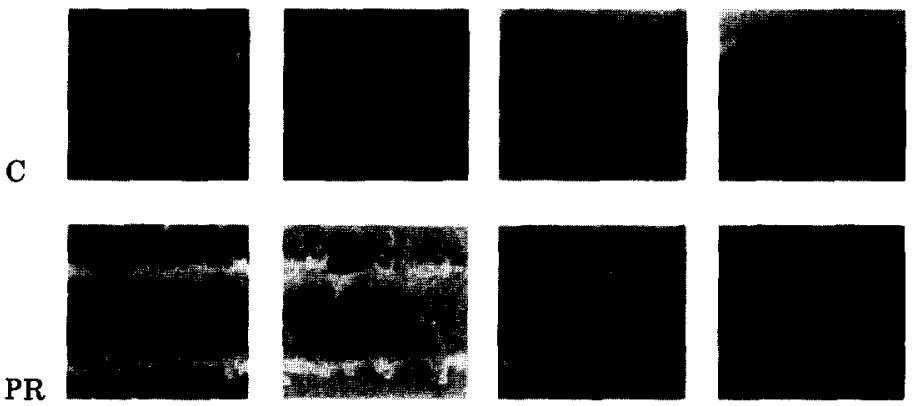

FN
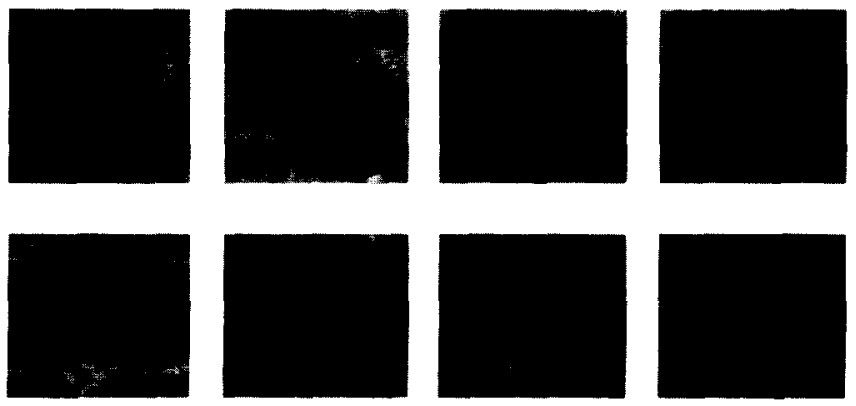

SI
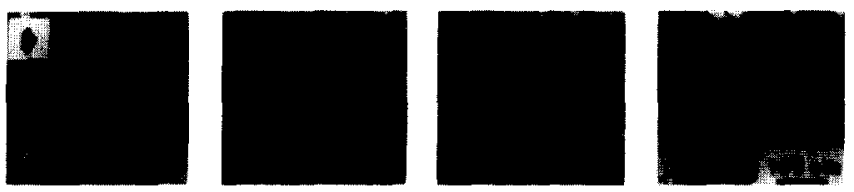

(a)

(b)

(c)

(d)

Fig. 5. Scanning electron micrographs of wear tracks of C, PR, FN, I and SI for a normal load of $8 \mathrm{~N}$ at (a) 0 , (b) 300 , (c) 600 and (d) $900 \mathrm{~h}$. The arrow indicates the direction of sliding.

Similar wear track data were obtained for $\mathrm{C}$ and $\mathrm{PR}$. The transition loads from class 1 to class 4 modes of surface failure are listed in Table 2. Scanning electron micrographs of wear tracks at a normal load of $8 \mathrm{~N}$ are shown in Fig. 5.

The wear track widths of the two conventional composites C and PR decreased after 300 and $600 \mathrm{~h}$ of aging. After $900 \mathrm{~h}$ of aging the wear tracks were wider at lower normal loads but narrower at higher normal loads than those of the unaged samples.

The microfilled composites showed an initial decrease in wear track width on aging and then the track widths approached those of the unaged samples on further aging. There were differences in the wear track widths between each aged and unaged microfilled composite and between the microfilled composites.

The two conventional composites had similar transition loads from class 1 to class 4 modes of surface failure. Both had lower transition loads 
TABLE 2

Transition load from class 1 to class 4 modes of surface failure for aged and unaged dental composites

\begin{tabular}{llllll}
\hline Condition & \multicolumn{5}{l}{ Material transition load $(\mathrm{N})$} \\
\cline { 2 - 6 } & $C$ & $P R$ & $F N$ & $I$ & $S I$ \\
\hline Unaged & $2.8(0.5)$ & $2.3(0.5)$ & $8.0(0.6)$ & $4.3(1.5)$ & $7.0(1.7)$ \\
$300 \mathrm{~h}$ & $1.8(0.5)$ & $1.5(0.0)$ & $3.3(0.5)$ & $4.3(0.5)$ & $6.0(0.6)$ \\
$600 \mathrm{~h}$ & $1.5(0.0)$ & $1.5(0.0)$ & $2.8(0.5)$ & $5.0(1.3)$ & $5.0(0.6)$ \\
$900 \mathrm{~h}$ & $1.5(0.0)$ & $1.5(0.0)$ & $3.0(0.6)$ & $4.3(0.5)$ & $2.0(0.6)$ \\
\hline
\end{tabular}

The mean values of the transition load are given with the standard deviations in parentheses.

The values connected by the same vertical line are not significantly different at the $95 \%$ level of confidence.

after accelerated aging. There was no significant difference between the transition loads for the composites aged for 300,600 and $900 \mathrm{~h}$, but they were significantly different from those of the unaged composites.

The effect of aging on the transition loads of the three microfilled composites was different for each composite. The transition load for FN decreased from 8 to $3 \mathrm{~N}$ on aging for $300 \mathrm{~h}$ and then there was no further change. There were no significant differences in the transition loads for aged and unaged I. The transition load for SI showed gradual changes. There was no significant difference between unaged samples and $300 \mathrm{~h}$ samples, nor between 300 and $600 \mathrm{~h}$ samples. The transition load for SI at $900 \mathrm{~h}$ was significantly lower than that of any other SI sample.

The surface morphology of the composite materials was altered by accelerated aging conditions. Changes in morphology became more severe with increased aging as shown in Fig. 6 for the conventional composites and Fig. 7 for the microfilled composites. Degradation of the conventional composites was characterized by the formation of microcracks and exposure and loss of filler particles over the entire surface. Degradation of the microfilled composites was characterized initially by the formation of isolated microcracks that became more extensive with continued aging.

\section{Discussion}

Accelerated aging of dental composites causes chemical degradation of the surface characterized by microcracks and exposure and loss of filler particles. The degradation causes changes in the mechanical properties of the surface layer characterized by lower track width, lower transition load and greater loss of material during single-pass sliding.

The composition of the composites appears to influence their chemical degradation. The conventional composites $\mathrm{C}$ and $\mathrm{PR}$ contain $\mathbf{7 6 . 2 \%}$ and $\mathbf{7 8 . 4 \%}$ 

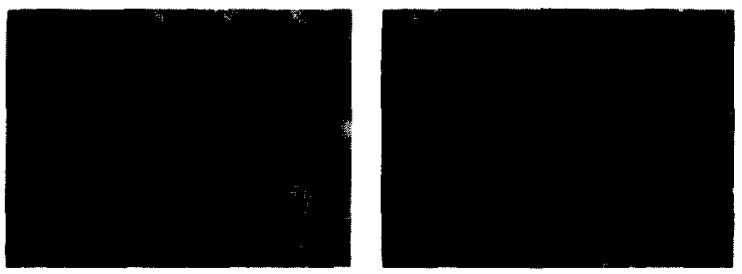

(a)
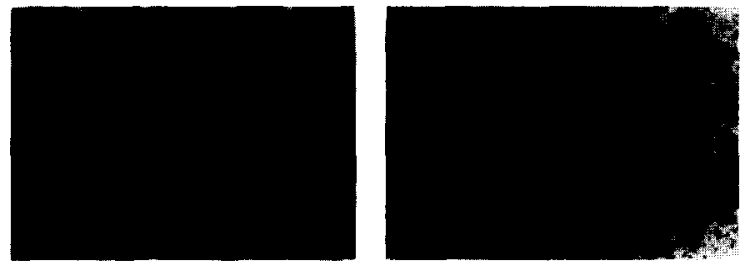

(b)
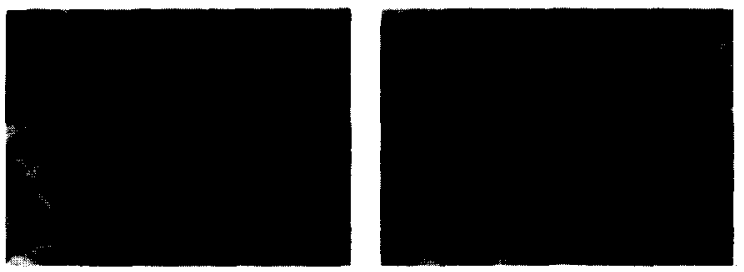

(c)
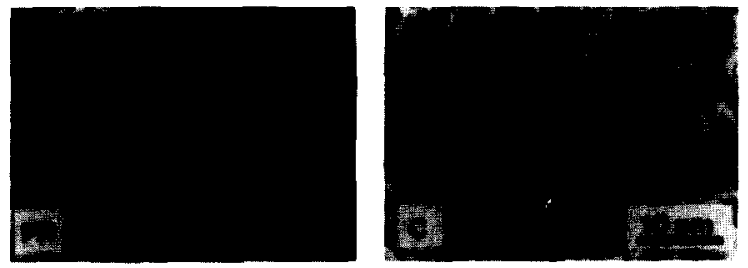

(d)

Fig. 6. Scanning electron micrographs of surface morphology of $P R$ and $C$ at (a) 0 , (b) 300 , (c) 600 and (d) $900 \mathrm{~h}$.

by weight of filler particles respectively that are several microns in size [9] . The microfilled composites FN, I and SI contain $33.2 \%, 37.2 \%$ and $49.7 \%$ by weight of silica particles respectively that are less than $1 \mu \mathrm{m}$ in size. The polymer matrix of the composites is a dimethacrylate containing Bisphenol A, with the exception of I which has a urethane dimethacrylate polymer matrix. The conventional composites appeared to be most susceptible to degradation, whereas the microfilled composite with the urethane dimethacrylate matrix appeared to be the least susceptible. 

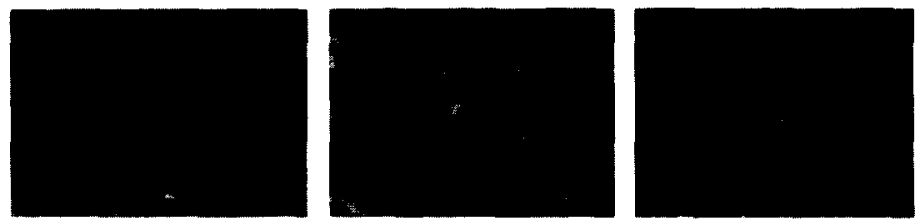

(a)
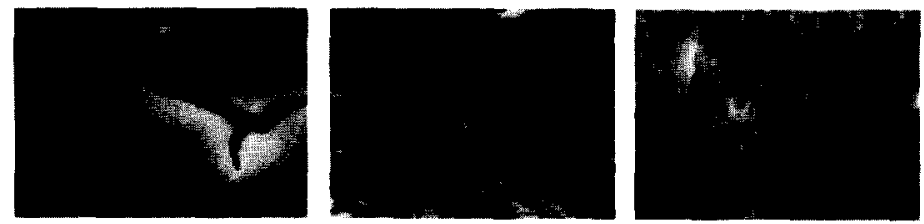

(b)
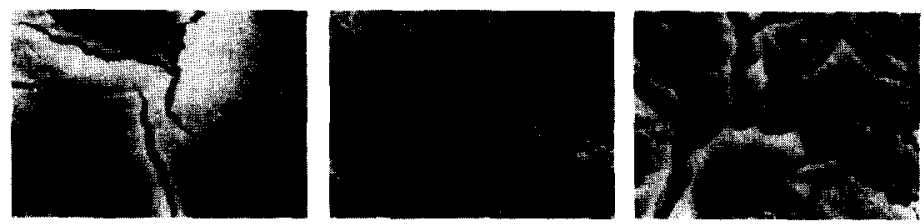

(c)
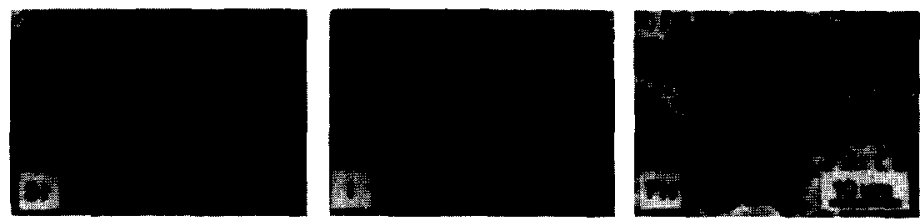

(d)

Fig. 7. Scanning electron micrographs of surface morphology of SI, I and FN at (a) 0 , (b) 300 , (c) 600 and (d) $900 \mathrm{~h}$.

Composite restorations in the oral environment are subject to aging, although the conditions are not identical with the in vitro conditions used in this investigation. The rate of surface degradation in vivo is slow; thus, excess wear may not be noticeable until months after the placement of the restoration. However, a degraded surface layer would be removed more easily by abrasion, erosion or other mechanisms of wear. The subsequent exposure of a freshly worn surface to the degradation process would continue the cycle.

\section{Conclusions}

Surface morphology and wear characteristics of dental composite restorative materials were studied by accelerated aging in vitro. The observed 
changes in wear track widths, transition loads and modes of surface failure caused by single-pass sliding were attributed to surface degradation of the dental composites as a result of aging.

\section{Acknowledgment}

This investigation was supported by U.S. Public Health Service Grant DE03416 from the National Institute of Dental Research, National Institutes of Health, Bethesda, MD 20205.

\section{References}

1 J. M. Powers, J. C. Roberts and R. G. Craig, Surface failure of commercial and experimental restorative resins, J. Dent. Res., 55 (1976) 432 - 436.

2 P. L. Fan, J. M. Powers and R. G. Craig, In vitro wear of microfilled and visible lightcured composites, J. Dent. Res., 58 (1979) 2116 - 2119.

3 R. P. Kusy and K. F. Leinfelder, Microstructure of posterior restoration of composite resin after clinical wear, Oper. Dent., 5 (1980) 90 - 94.

4 W. J. O'Brien and J. Yee, Jr., Surface structure of class II, J. Dent. Res., Spec. Issue A, 58 (1979) 327

5 J. M. Powers and P. L. Fan, Erosion of composite resins, J. Dent. Res., 59 (1980) $815-819$.

6 P. L. Fan and J. M. Powers, In vitro wear of aged composite restorative materials, $J$. Dent. Res., 59 (1980) 2066 - 2070.

7 B. J. Finney, Statistical Method in Biological Assay, Hafner, New York, 1964.

8 R. R. Sokal and F. J. Rohlf, Biometry, Freeman, San Francisco, 1969.

9 P. L. Fan, J. B. Dennison and J. M. Powers, Properties of conventional and microfilled composites, Mich. Dent. Assoc. J., 62 (1980) 455 - 457. 